\title{
Q
}

ISSN 2278-0211 (Online)

\section{Gĩtigania Nominal Tone}

\author{
Muchiri Kinya Dorcas \\ M.A Student, Department of Humanities, Chuka University, Kenya \\ Dr. Nancy Mbaka \\ Lecturer, Department of Humanities, Chuka University, Kenya
}

\begin{abstract}
:
Tone is a suprasegmental feature that refers to the use of pitch in a language to distinguish lexical or grammatical meaning. Tone plays a crucial role in distinguishing meaning, word classes, tenses as well as different moods inGĩtigania language. This paper describesnominal tone in Gĩtigania, focusing on the tonal patterns as well as the effect of tone on meaning and word classes. The tonally distinctive monosyllabic nouns in Gĩtigania demonstrate both high and low tonal patterns while the bi-syllabic nouns show the HH, LL, HL, and LH tonal alterations. The tri-syllabic nouns on the other hand, demonstrate LHH, LLL, and HHH tone patterns, where similar tones are collapsed in correspondence with the Obligatory Contour Principle. Not only does tone distinguish Gĩtigania lexical items with similar segmental composition, but also brings about a difference in meaning, an indication that tone is minimally contrasting. The Autosegmental Phonological Theory as propounded by Goldsmith (1990) was employed in analysing, interpreting and discussing the data collected. The target population was the nouns in Gĩtigania. This paper used the Judgmental sampling procedure since it allows the researcher to choose desirable and reliable sample members based on one's knowledge and judgement. Approximately one hundred Gĩtiganianouns generated through non-participant observation and introspection were selected for inclusion in this paper.The findings of this paper are anticipated to add to the existing literature in the field of Phonology.
\end{abstract}

Keywords: Tone, suprasegmental features, autosegmental

\section{Introduction}

This paper explores and analyses Gĩtigania nouns for tone depending on the number of syllables in each lexical item using the Autosegmental representations. Tone is marked using diacritics and nouns classified on basis of lexical function of tone. Based on the fact that the class prefix in most Bantu nouns, Gĩtigania being no exceptional takes a low tone, analysis of nominal tone is therefore based on stem syllables. The tone patterns established are helpful in determining the form of tones in Gĩtigania.

\subsection{Tone}

Typically, Bantu languages are tonal while tone is considered an integral part in most African languages. Just like consonants and vowels, tone may signal minimal distinctions on syllables and words. Tone languages employ pitch to distinguish word meaning or convey grammatical distinction. Tone is a distinctive feature among Bantu languages, Gĩtigania included. A tonal language is one that employs levels to pitch to make lexical or syntactic difference. This is to mean that tone performs both lexical and grammatical functions. Based on the type of tones exhibited, a distinction between tone languages, that is level and contour can be drawn. Languages with contour tones demonstrate pitch movement whose tones include: Falling (HL), Rising (LH), Falling-Rising (HLH) and Rising-Falling (LHL) while those with level tones take steady pitches like high (H) and low (L) (Pike 1948). Therefore, level and contour tones distinguish between register tone languages and contour tone languages respectively. Hyman (2010) identifies three stages of studying a tone system which include; determining the surface tone contrast by considering words in isolation, discovering tone alterations on basis of paradigmatic and phrasal contexts and finally interpreting the data to produce analysis. In her study, Mutiga (2002) states that the absence of tone marking in the orthography of a tone language is a challenge both to the reader and writer of that language. This is because one is forced to rely on the context for meaning or else make guesses. As a result, reading and acquisition of literacy skills become difficult thus, diminished interest in reading and writing in such languages. She further argues that lack of tone marking in tonal languages is the inevitable failure to understand and be understood; a factor that may result to communication breakdown. Therefore, to ease the reading and writing in such languages, tone should be incorporated in the orthography of tonal languages.

\subsection{Nominal Tone}

Bantu tonology is a field that has attracted considerable research in the recent past with most studies addressing noun tonology. Hyman (1976) states that tone patterns of nouns in various Bantu languages are described with the aim of 
determining morphophonemic rules required to derive the various tonal alternations. Hyman (1976) focuses on the problems surrounding the phenomena of tonal downstep in various Bantu languages. These problems are linked to the origin, classification, effects and analysis of downstep. Aunio (2015) states that in proto-Bantu languages, tones are specified for each vowel of the noun stem. Thus, monomoraic noun stems have two different tonal patterns (H and L). On the other hand, bimoraic noun stems have four patterns namely: HH, HL, LH, and LL. Phillipson (1998) argues that monosyllabic stems have two tonal patterns $(H \& \emptyset)$ while bisyllabic stems have three tonal patterns $(H \emptyset, \emptyset H, \emptyset \emptyset)$. This indicates that the number of possible tonal patterns is the number of stem syllables plus one $(n+1)$. Their studies provided a great insight with regard to the nature of tone and tone patterning in Gĩtigania. Tone serves the function of distinguishing meaning as well as word classes as illustrated below using an example from Igbo, a language classified as an AtlanticCongo language which is a sub-group of Niger-Congo language family, spoken in the Eastern part of Nigeria, Nkamigbo (2010).

$\begin{array}{ll}\text { Word } & \text { Gloss } \\ \text { Àkwà } & \text { 'bed/bridge' } \\ \text { Akwà } & \text { 'cloth' } \\ \text { Akwa } & \text { 'crying' } \\ \text { Àkwa } & \text { 'egg' } \\ \text { Ègó } & \text { 'buying' } \\ \text { Égo } & \text { 'money' } \\ \text { Ìsì } & \text { 'blindness' } \\ \text { Isi } & \text { 'head' } \\ \text { Isì } & \text { 'smell' } \\ \text { Isí } & \text { 'to cook' } \\ \text { Okè } & \text { 'boundary' } \\ \text { Oke } & \text { 'male' } \\ \text { Òke } & \text { 'rat' } \\ \text { Òkè } & \text { 'share' } \\ \text { Òzo } & \text { 'again' } \\ \text { Ózò } & \text { 'gorilla' }\end{array}$

\subsection{Theoretical Framework}

This paper adopted the Goldsmith (1976) Autosegmental Phonological Theory (APT) in the phonological representation of tone in Gĩtigania. This is because it presents the distinctive feature of tone as independent from any segmental representation.Goldsmith (1976) observes that APT is an improvement of the theory of generative phonology developed by Chomsky and Halle (1968) in their book; The Sound Patterns of English (SPE). The SPE model however, represents sounds in slices or segments which consist of unordered bundles of features which are linearly ordered. Chomsky and Halle (1968) assumed that features such as tone and stress, and possibly vowel harmony are super-imposed on the segment and that both segmental and suprasegmentals were arranged in a row one after another. This assumption that phonological representations consisted of linear segmental and suprasegmental levels was taken for granted, and the question on how these two levels related to each other was not fully addressed. However, around the mid-1970s, a number of language researchers started to focus on the relationship between segmental and suprasegmentals. APT was initially formalized to address tonal phenomenon. It is a multi-linear approach to phonological representations as opposed to the linear one of SPE model. In APT, distinctive features are viewed as independent from any segmental representations. Goldsmith (1990) observes that there is no always one to one mapping of tones to syllables. Two tones could occupy one syllable and two syllables could be occupied by one tone. The ATP describes features as autosegments. The suprasegmental features which are the focus of this study are autosegments thus, can be analysed using ATP terms.

\section{Methodology}

The target population comprised all nouns and verbs in Gĩtigania language. Judgment sampling approach as explained by Smith (1984) was used in this study, because it allowed the researcher to choose desirable and reliable sample members on basis of one's knowledge and judgment. Three respondents; native speakers with reliable competence in Gĩtigania were selected on the basis of their accessibility during the research period in order to ascertain the correctness of tone from the recorded list of word forms. The sample size consisted of a hundred nouns and verbs from Gĩtigania, which was adequate data for analysis. The research adopted the use of oral interview, non-participant observation and introspection to collect data from all the respondents. The data generated was then recorded through note making and tape recording. Tone was further detected through humming and whistling of the words. It was then transcribed, classified and analysed on basis of syllables and tonal functions.

\section{Gĩtigania Noun}

Gĩtigania nouns are classified into different noun classes which are similar to most Bantu languages whose classification is mainly based on morphological gender, though there is partial semantic correlation between some of the class prefixes. As Marete (1981) observes, the semantic correlations between the classes indicate the basis of the original noun-class system in the Proto-Bantu. The class naming follows the singular-plural pairs formed by the singular and plural prefixes of the members of the corresponding nominal groups. 


\subsection{Tone Patterns in Monosyllabic Stem Nouns}

Monosyllables are words comprising of a single syllable. In Gĩtigania, there is a wide range of nouns with monosyllabic stems as illustrated below.

\begin{tabular}{|c|c|c|}
\hline Word & Gloss & Noun Class \\
\hline A[ká] & 'women' & class I/2 \\
\hline A[ná] & 'children' & class $1 / 2$ \\
\hline I[nyá] & 'energy' & class $7 / 8$ \\
\hline I[nyà] & 'four' & class $7 / 8$ \\
\hline$\tilde{I}\left[\tilde{I}^{\mathrm{L}} \mathrm{tí}\right]$ & 'chair' & class $7 / 8$ \\
\hline M[aú] & 'intestines' & class $9 / 10$ \\
\hline M[àù] & 'wasps' & class $9 / 10$ \\
\hline M[àrà] & 'intestines' & class $9 / 10$ \\
\hline M[àrá] & 'patches' & class $9 / 10$ \\
\hline M[bàũ] & 'timber' & class $9 / 10$ \\
\hline M[bàúu] & 'wild cat' & class $9 / 10$ \\
\hline Mũ[kà] & 'woman' & class $1 / 2$ \\
\hline Mũ[kwá] & 'bunch of bananas' & class $3 / 4$ \\
\hline Mũ[kwà] & 'rope' & class $3 / 4$ \\
\hline Mũ[rì] & 'root' & class $3 / 4$ \\
\hline Mũ[rǐ] & 'rope' & class $3 / 4$ \\
\hline Mũ[tú] & 'flour' & class $3 / 4$ \\
\hline $\mathrm{N}$ [dá] & 'Louse' & class $9 / 10$ \\
\hline $\mathrm{N}$ [dà] & 'stomach' & class $9 / 10$ \\
\hline $\mathrm{N}$ [dèwà] & 'bull' & class $9 / 10$ \\
\hline N[dèwá] & 'name of a person' & class $9 / 10$ \\
\hline $\mathrm{N}[$ dù $]$ & 'beast' & class $9 / 10$ \\
\hline $\mathrm{N}[\mathrm{dǔ}]$ & 'relations' & class $9 / 10$ \\
\hline $\mathrm{N}[\mathrm{j} a \tilde{u}]$ & 'calf' & class $9 / 10$ \\
\hline $\mathrm{N}$ [jaû́] & 'name of a person' & class $9 / 10$ \\
\hline N[jĩrá] & 'name of a person' & class $9 / 10$ \\
\hline $\mathrm{N}$ [jĩrà] & 'road' & class $9 / 10$ \\
\hline Ri[kó] & 'kitchen' & class $5 / 6$ \\
\hline Thà & 'watch' & - \\
\hline Thá & 'weed species' & - \\
\hline
\end{tabular}

Taking example one to represent the data in 2 above, tone labels can be used to illustrate the tone patterns which are further mapped on tonal charts to make a structural representation in regard to the Autosegmental Phonological theory as shown respectively:

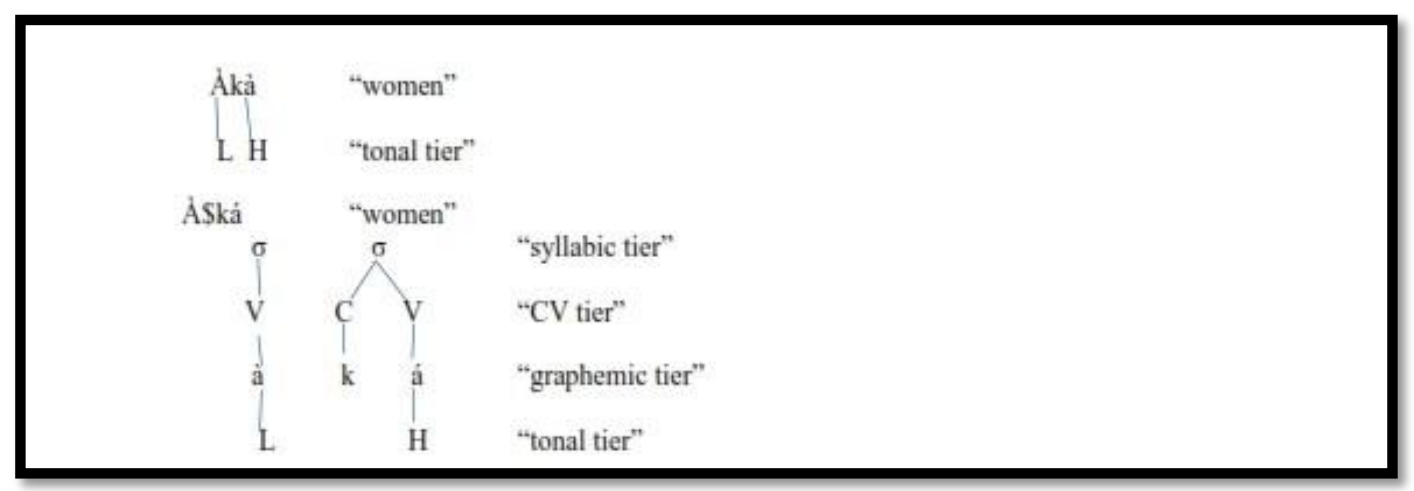

Figure 1

From the above data, the surface tone of the class prefix in Gĩtigania is low (L) while the monosyllabic stems take the primary high tone, Low and a contour LH. In addition, there is a wide range of minimally contrasting monosyllabic stemmed nouns in Gĩtigania, words whose difference is marked by tone.

\subsection{Tone Patterns in Bisyllabic Stem Nouns}

There are several nouns with bisyllabic stems in Gĩtigania language whose structure varies in the shapes of CVCV to VCV.

$\begin{array}{lll}\text { Word } & \text { Gloss } & \text { Noun class } \\ \mathrm{A}[\text { chùì] } & \text { 'chick' } & \text { class 12/13 } \\ \mathrm{A}[\text { chùí] } & \text { 'name of a person' } & \text { class 12/13 }\end{array}$




\begin{tabular}{|c|c|c|}
\hline Ĩ[chúnkwà] & 'an orange' & class $5 / 6$ \\
\hline$\tilde{I}[$ kòmbe] & 'cup' & class $7 / 8$ \\
\hline$\tilde{I}[$ kùndì] & 'a group' & class $7 / 8$ \\
\hline$\tilde{I}[$ [kúndí] & 'name of a person' & class $7 / 8$ \\
\hline$\tilde{I}[$ ríà] & 'milk' & class $5 / 6$ \\
\hline$\tilde{I}[$ rì̀ $]$ & 'weed' & class $5 / 6$ \\
\hline Ka[bètì] & 'purse' & class $12 / 13$ \\
\hline Ka[bètí] & 'name of a person' & class $12 / 13$ \\
\hline $\mathrm{Ka}$ [ràmú] & 'pen' & class $12 / 13$ \\
\hline Kî[àlì] & 'cart' & class $7 / 8$ \\
\hline Kĩ[àlí] & 'daughter' & class $7 / 8$ \\
\hline Kĩ[àrá] & 'a finger' & class $7 / 8$ \\
\hline Kĩ[àrà] & 'a heap' & class $7 / 8$ \\
\hline Kĩ[árà] & 'infectious laughter' & class $7 / 8$ \\
\hline Kĩ[òrò] & 'branding tool' & class $7 / 8$ \\
\hline Kĩ[óró] & 'toilet' & class $7 / 8$ \\
\hline Kĩ[thùà] & 'a cripple' & class $7 / 8$ \\
\hline Kĩ[thúà] & 'hairy worm' & class $7 / 8$ \\
\hline Kĩ[ũlà] & 'a frog' & class $7 / 8$ \\
\hline Kĩ[úlá] & 'name of a person' & class $7 / 8$ \\
\hline Kĩ[ú́lú́] & 'lizard' & class $7 / 8$ \\
\hline Kĩ $[\tilde{u} l u \tilde{u}]$ & 'tyre' & class $7 / 8$ \\
\hline M[aìrì] & 'fencing brunches' & class $5 / 6$ \\
\hline M[aírí] & 'miles' & class $5 / 6$ \\
\hline M[aúrí] & 'lungs' & class $5 / 6$ \\
\hline M[aũrì] & 'prices' & class $5 / 6$ \\
\hline Mu[chìnkà] & ‘a fool' & class $3 / 4$ \\
\hline Mu[chínká] & 'fire arm' & class $3 / 4$ \\
\hline Mũ [chìrì] & 'French bean' & class $3 / 4$ \\
\hline Mũ[chírí] & 'name of a person' & class $3 / 4$ \\
\hline Mũ[ràngó] & 'door' & class $3 / 4$ \\
\hline Mũ[rĩmi] & 'a farmer' & class $1 / 2$ \\
\hline Mũ[rùrù] & 'egg york' & class $3 / 4$ \\
\hline Mũ[rùrú] & 'name of a person' & class $3 / 4$ \\
\hline Mũ[tèó] & 'trap' & class $3 / 4$ \\
\hline Mũ[thũrí] & 'euphorbia' & class $3 / 4$ \\
\hline Mũ[thũrì] & 'soup' & class $3 / 4$ \\
\hline $\mathrm{R}$ [ũító] & 'a wall' & class $11 / 10$ \\
\hline $\mathrm{R}$ [ũìtò] & 'residue' & class $11 / 10$ \\
\hline
\end{tabular}

Below are illustrations of tone labels and an AP structural representation of 3 above using one of the examples.

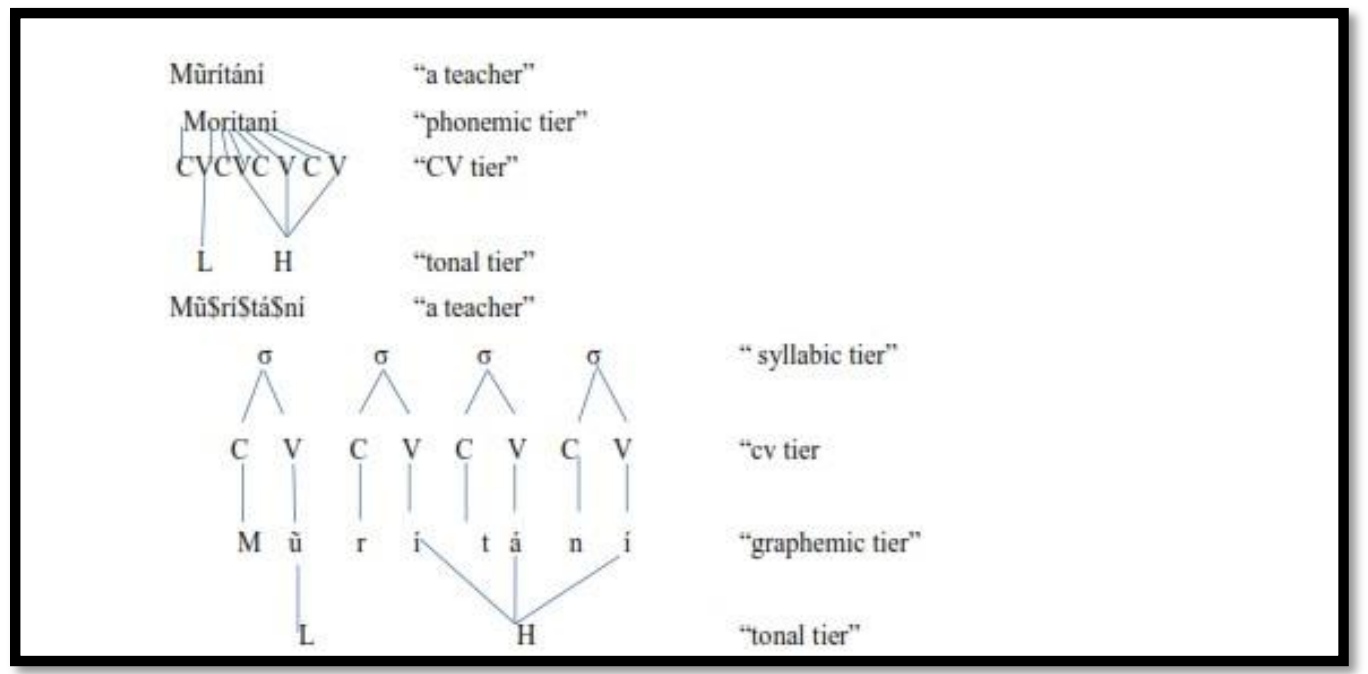

Figure 2

From the above examples, Gĩtigania demonstrates HH, LH, LL and HL tonal alterations amongst nouns with bisyllabic stems. This is in line with Kisserberth and Odden (2003) who state that in the bisyllabic stems, four tone patterns are reconstructed for Proto-Bantu: HH, HL, LL and LH. 


\subsection{Tone Patterns in Trisyllabic Stem Nouns}

Trisyllabic words consist of three syllables. There are few nouns in Gĩtigania that have trisyllabic stems. Below are the tonal patterns they demonstrate.

Word

Mũ[rítání]

Kĩ[thìóò]

Kĩ[thàngàchí]

Kĩ[thùrànó]

Mũ[kàrìà]'a guard'

Mũ[kàrìá]'name of a person'

Mũ[àrĩkì ]'castor oil plant'

Mũ[áríkí ]'ritualist'

Ĩ[tòèró] 'stew'

Ĩ[táràrû́] 'winnowing tray'

Ĩ[kùndĩkwá] 'a knot'
Gloss

'a teacher'

'a corner'

'a pumice stone'

'an election'
Noun class
class $1 / 2$
class $7 / 8$
class $7 / 8$
class $7 / 8$
class $1 / 2$
class $1 / 2$
class $3 / 4$
class $3 / 4$
class $7 / 8$
class $7 / 8$
class $7 / 8$

Taking the first example in 4 above, the following representation with tone labels can be used to illustrate the tone patterns. This is further mapped on tonal charts to make the structural representation in regard to the Autosegmental Phonological theory as illustrated.

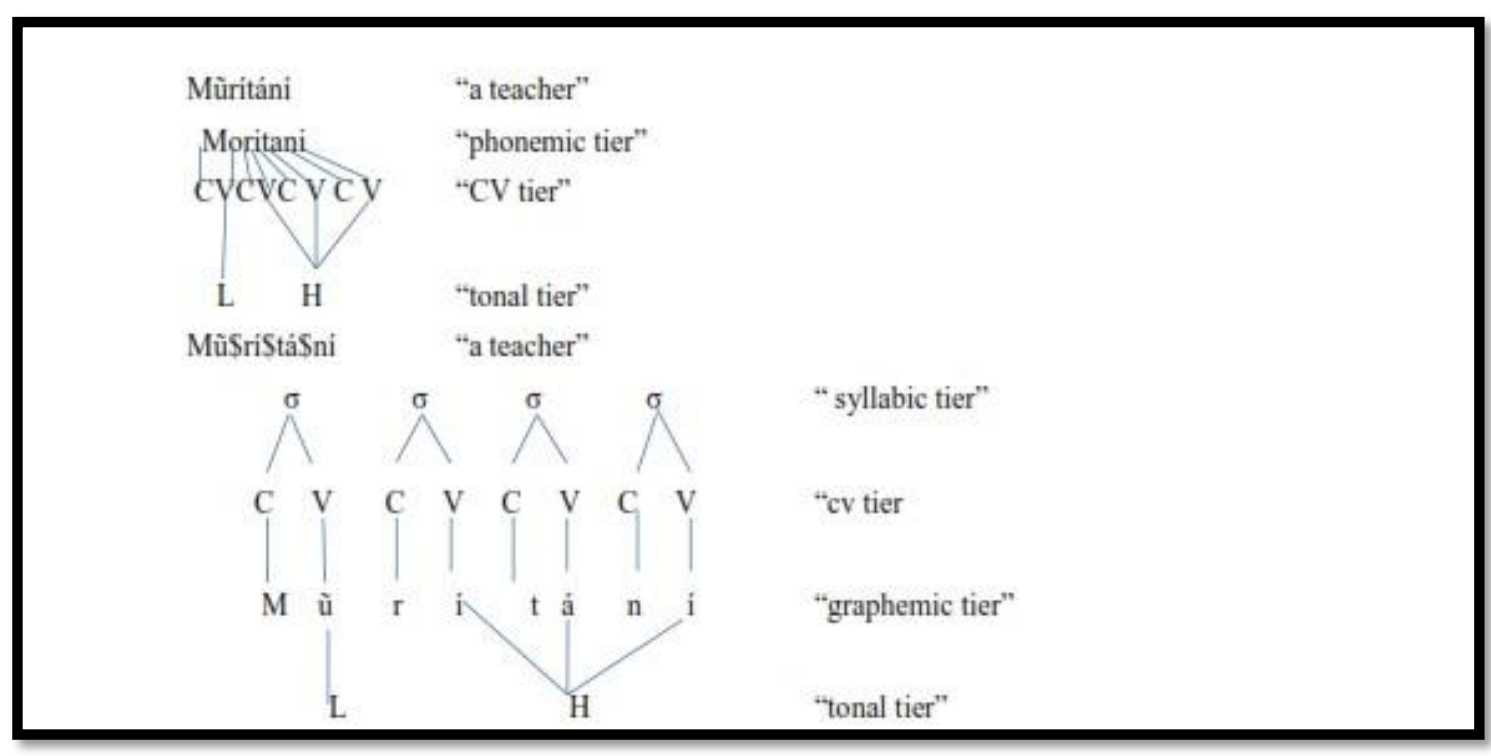

Figure 3

From the above data, Gĩtigania demonstrates high (H), low (L) LHL, and LLH tones in tri-syllabic stemmed nouns.

\subsection{Lexical Function of Tone}

Welmer (1973) posits that one of the functions of tone is to distinguish different lexical items in a language. He adds that lexical items that differ only in tone are different words just like words that differ in any other way. Thus, tones are phonemes serving a distinctive role just like consonants and vowels. Aderibigbe (2012) on the other hand states that tone performs part of the lexical information of a word which implies that a difference in pitch is used contrastively to signal a lexical difference such that phonemes or words with similar forms can be differentiated on basis of tone. Tone is therefore critical as variation could bring about a word of different meaning and word class

Tone serves a lexical function in Gĩtigania. This is demonstrated using minimal pairs obtained from the word classes under study. Other than tone being minimally distinctive in each grammatical category, it can also be used to distinguish grammatical categories or word classes. Distinctive lexical tone patterns are analysed on syllabic basis in an attempt to differentiate word meaning. In addition, the APT representations of distinctive lexical tone patterns are shown to highlight the lexical function of tone as demonstrated in the tonal tiers. Where lexical items are not given full APT representations, the distinctive tones and tone patterns are mapped onto the TBUs inherent in the CV tier in accordance to the Obligatory Contour Principle and the principle of association.

\subsubsection{LexicalFunction of Tone: Meaning}

Tone in Gĩtigania distinguishes meaning of identical segments or words within a word class. The following minimal pairs based on syllables, that is monosyllabic, bi-syllabic and tri-syllabic respectively are tonally distinctive. Tone labels and APT representations are used to highlight the lexical function of tone as illustrated. The tone patterns displayed are further mapped on tonal charts in regard to Autosegmental Phonological Theory to make structural representation as shown in the subsequent section. 


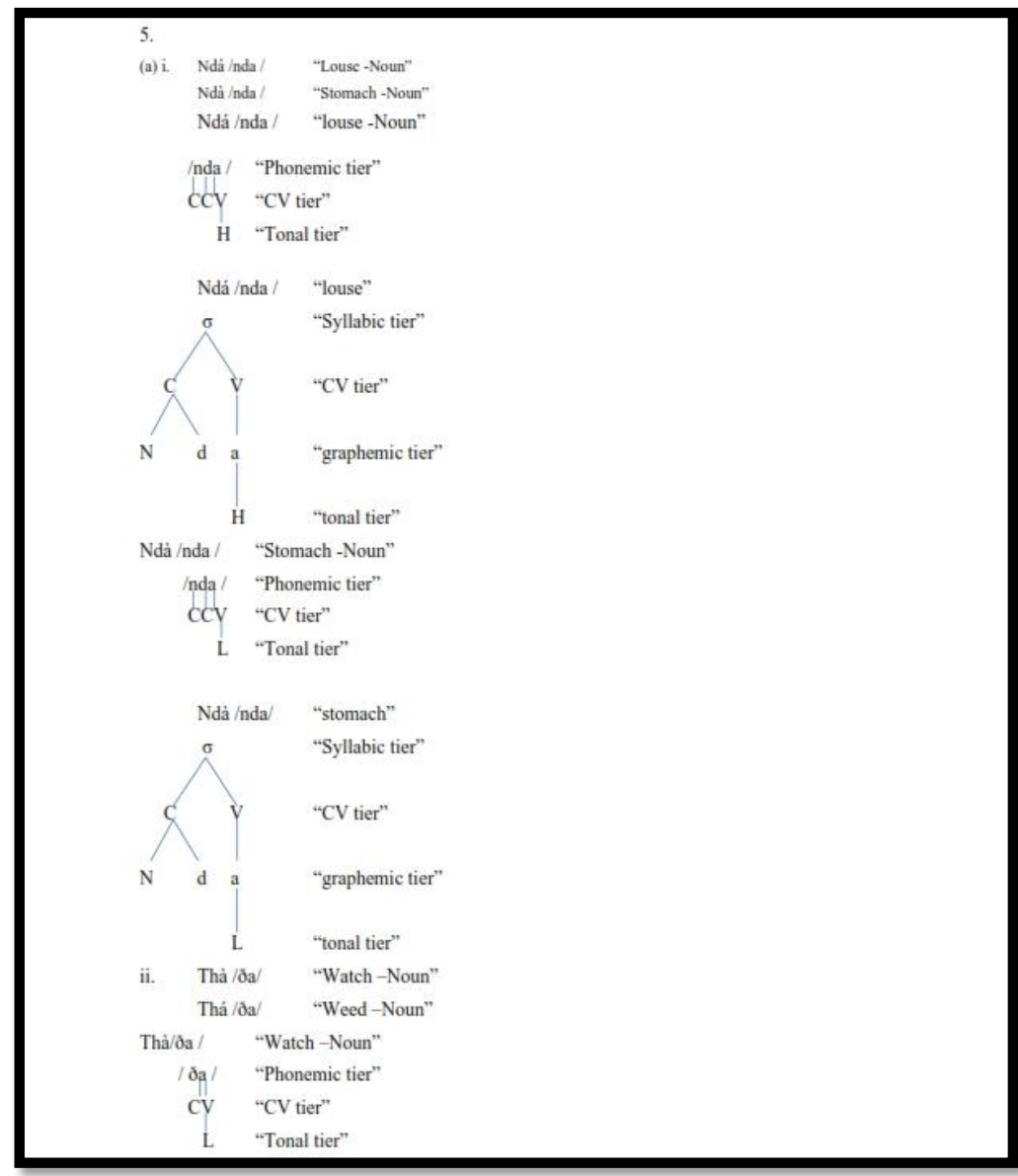

Figure 4

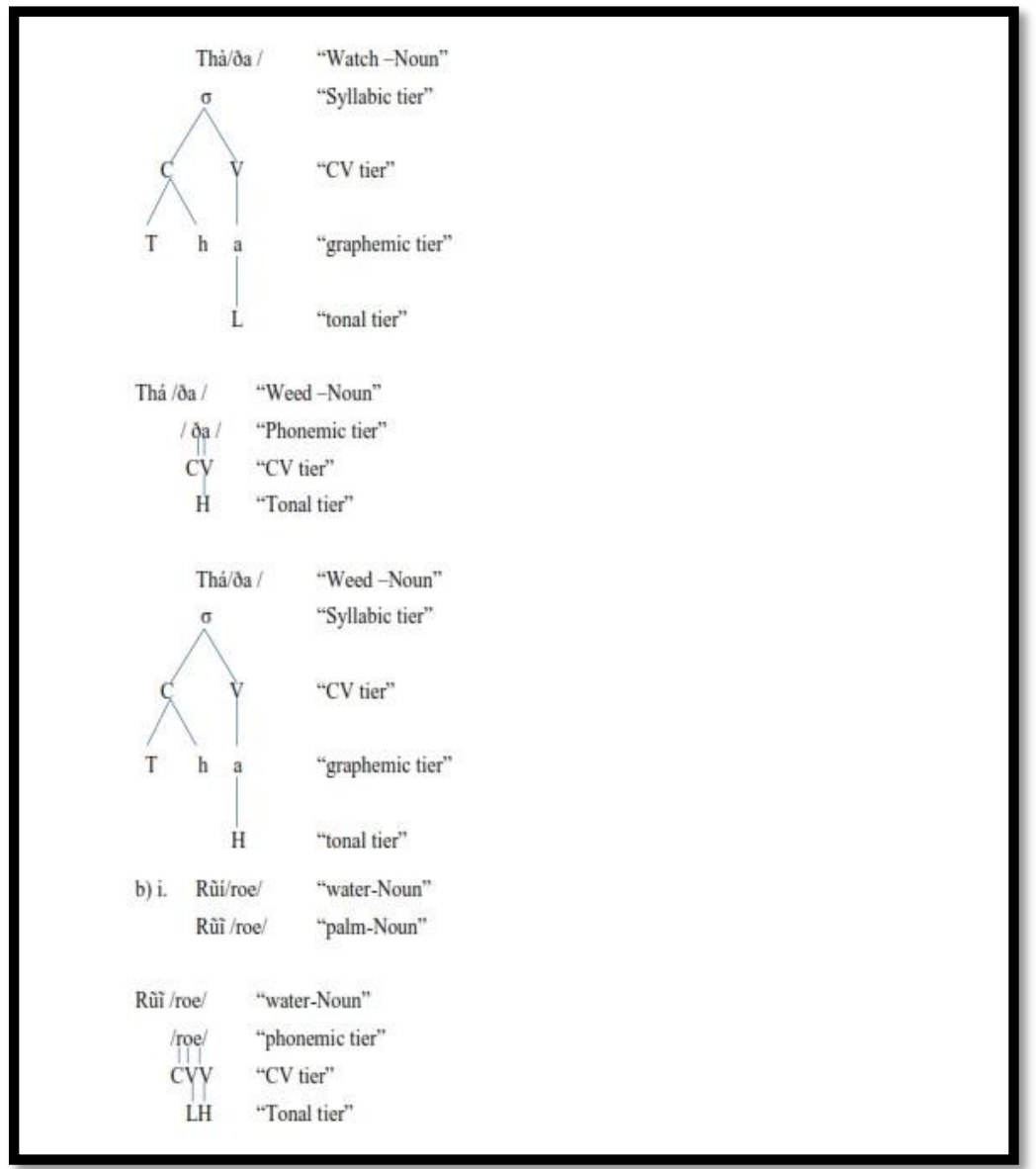

Figure 5 


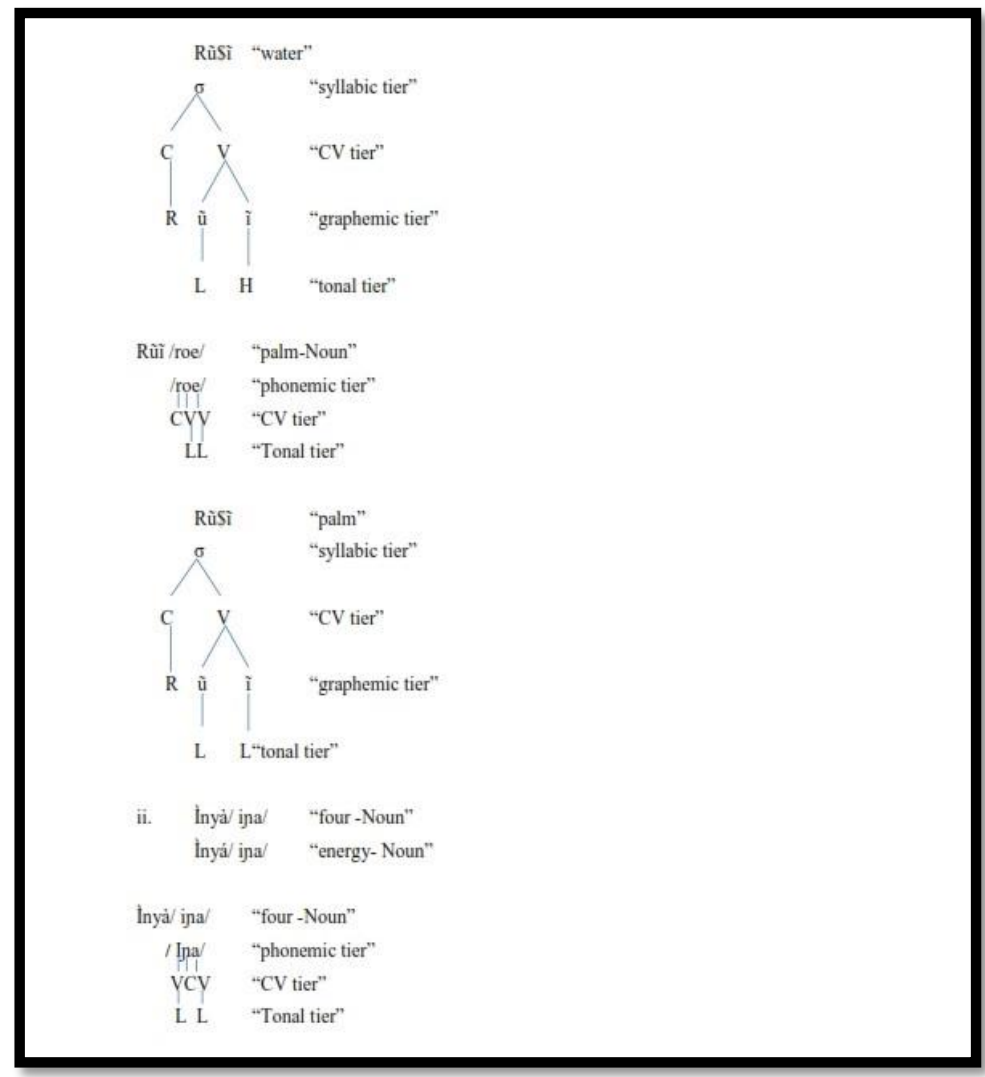

Figure 6

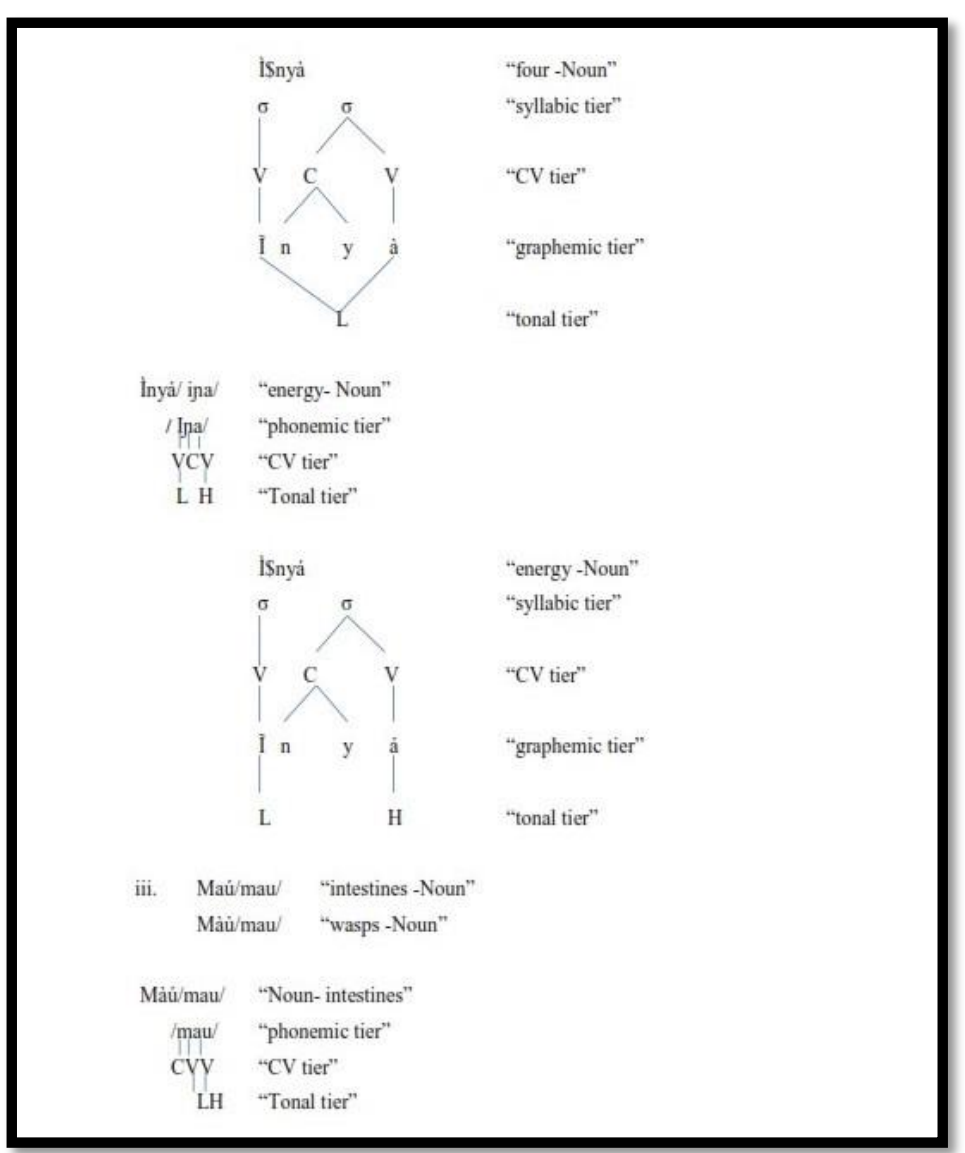

Figure 7 


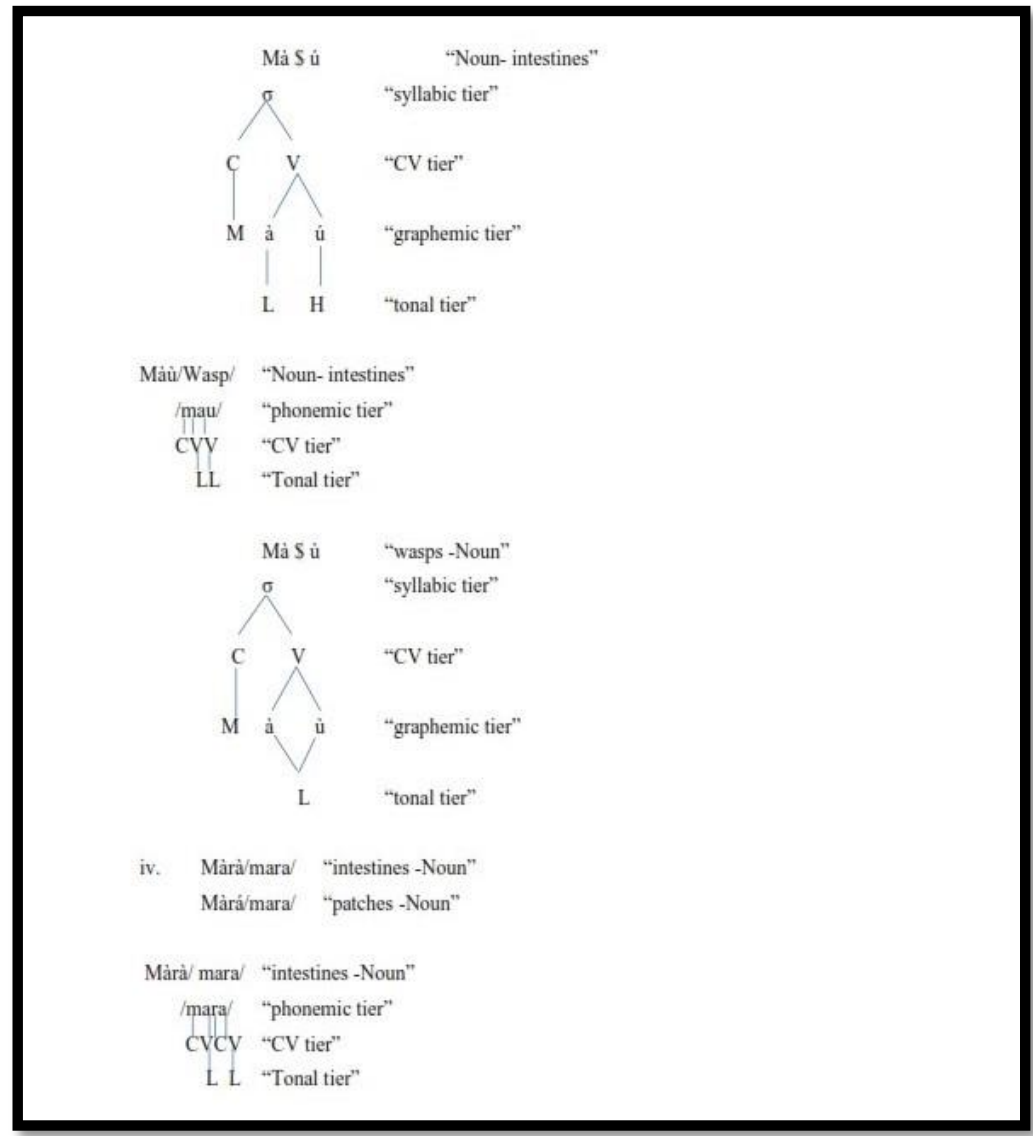

Figure 8

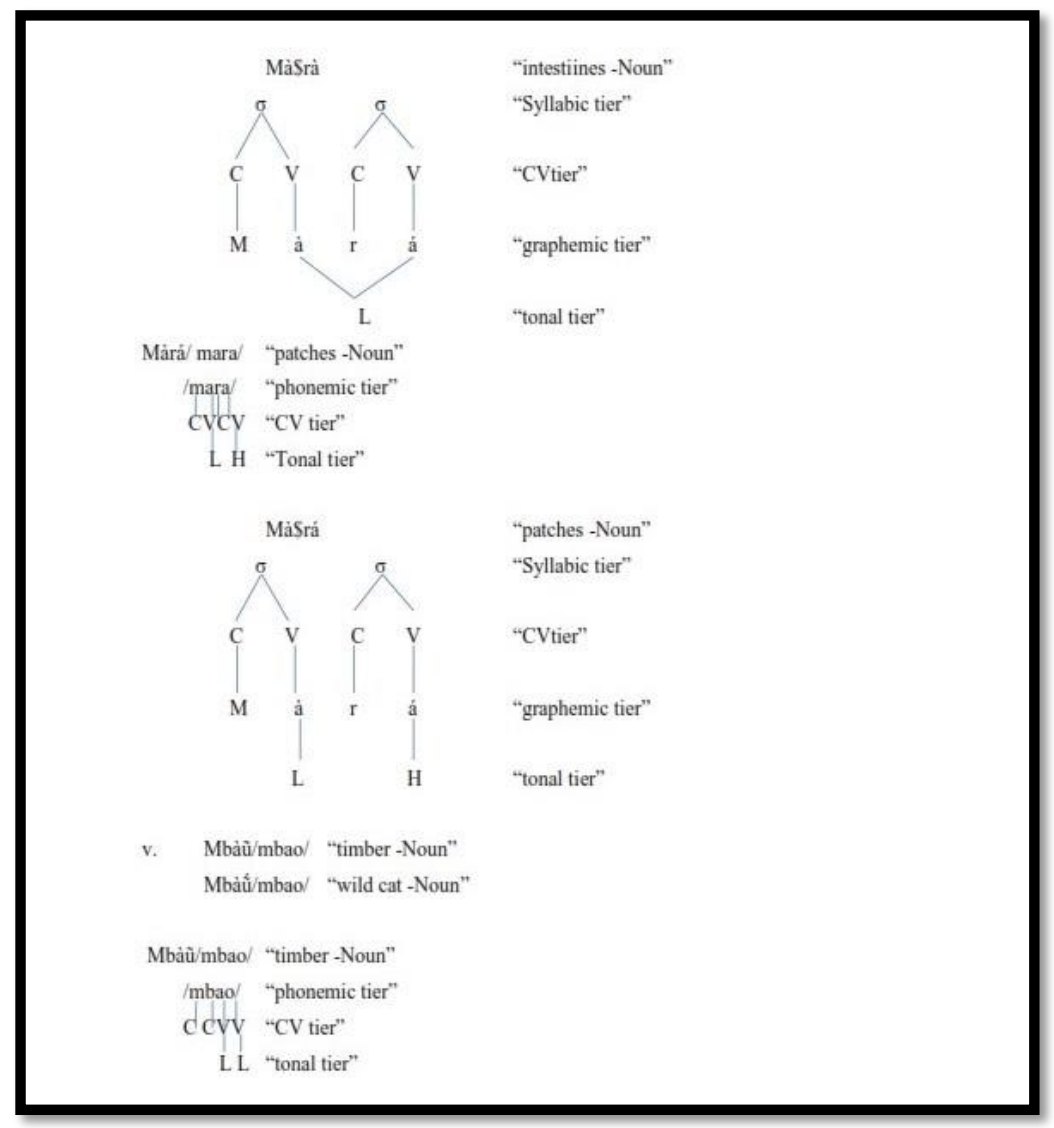

Figure 9 


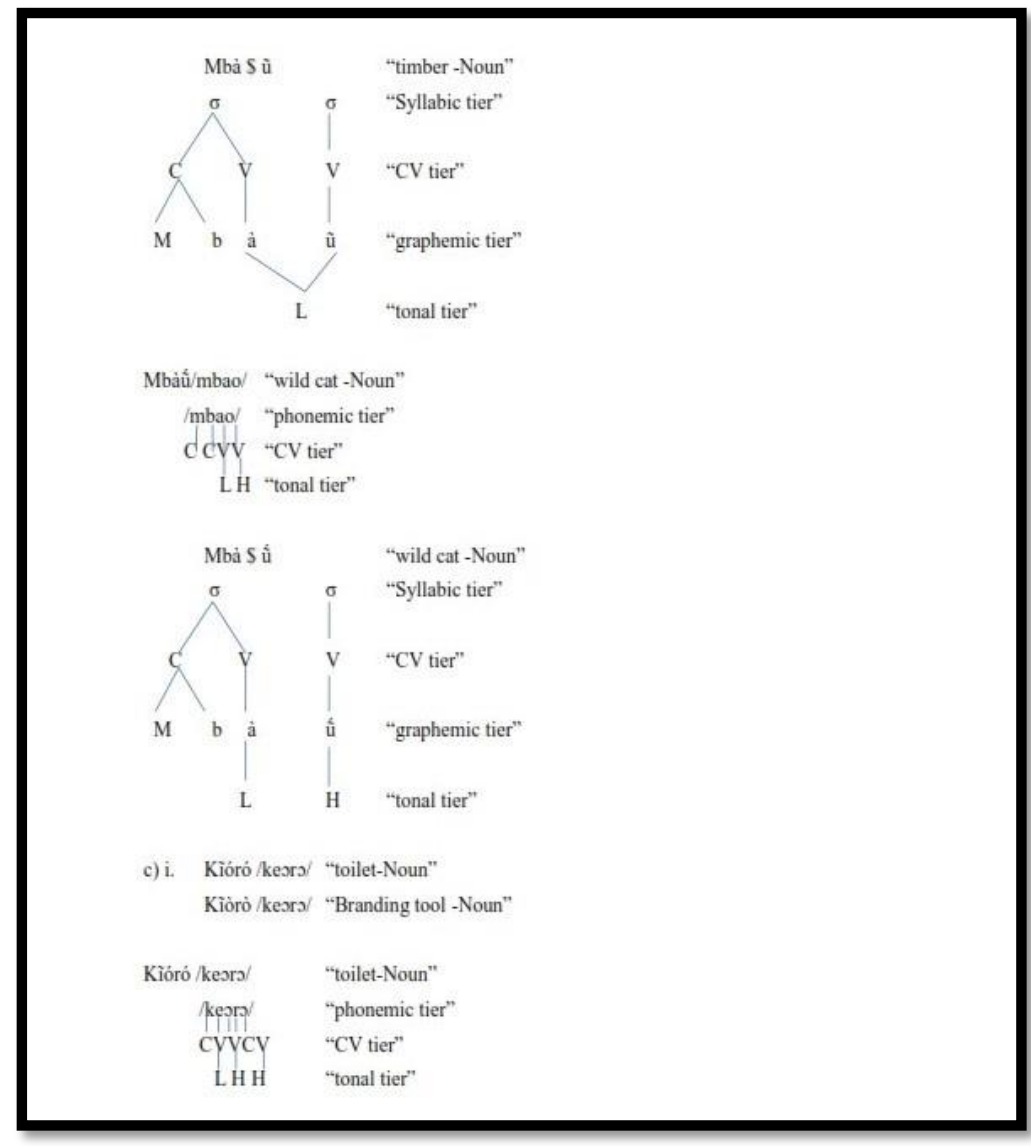

Figure 10

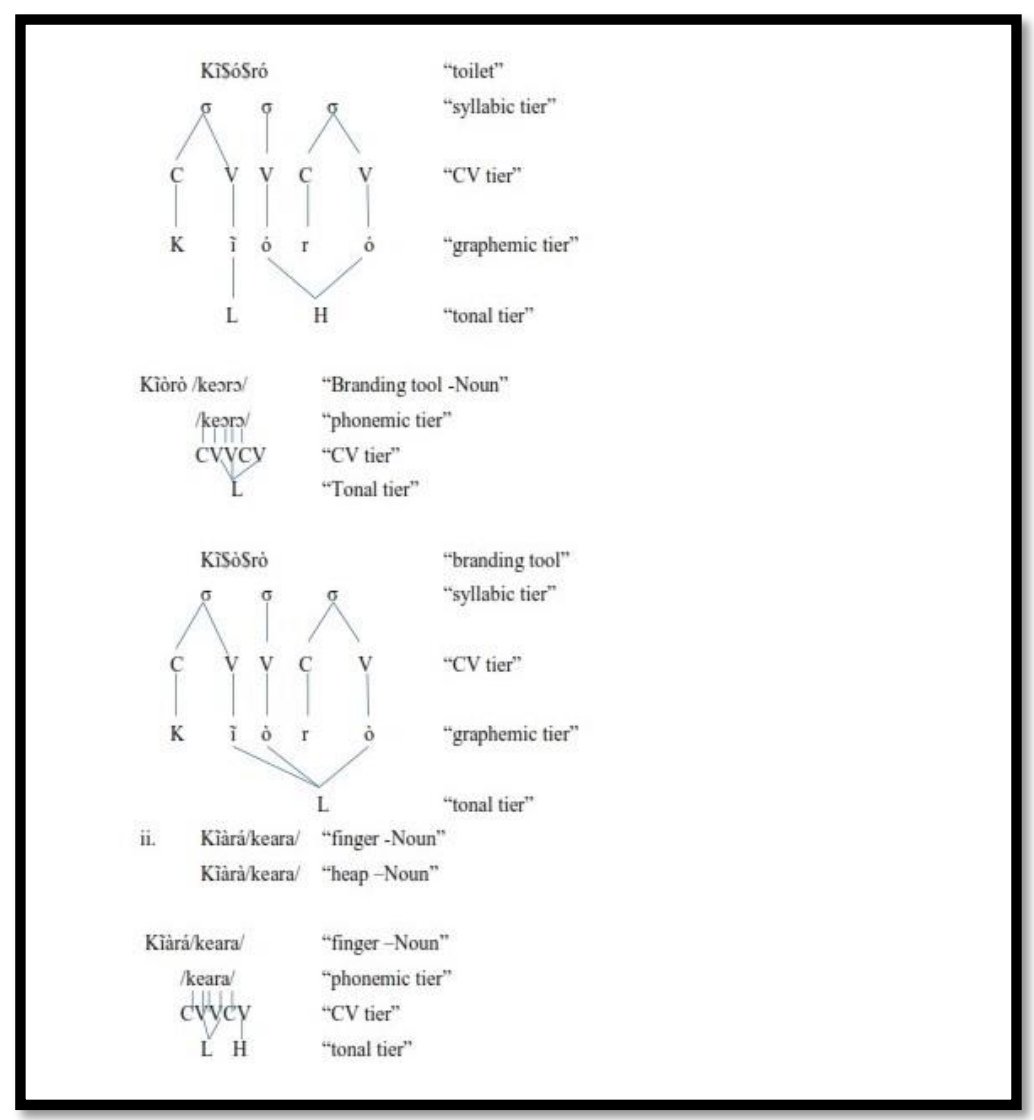

Figure 11 


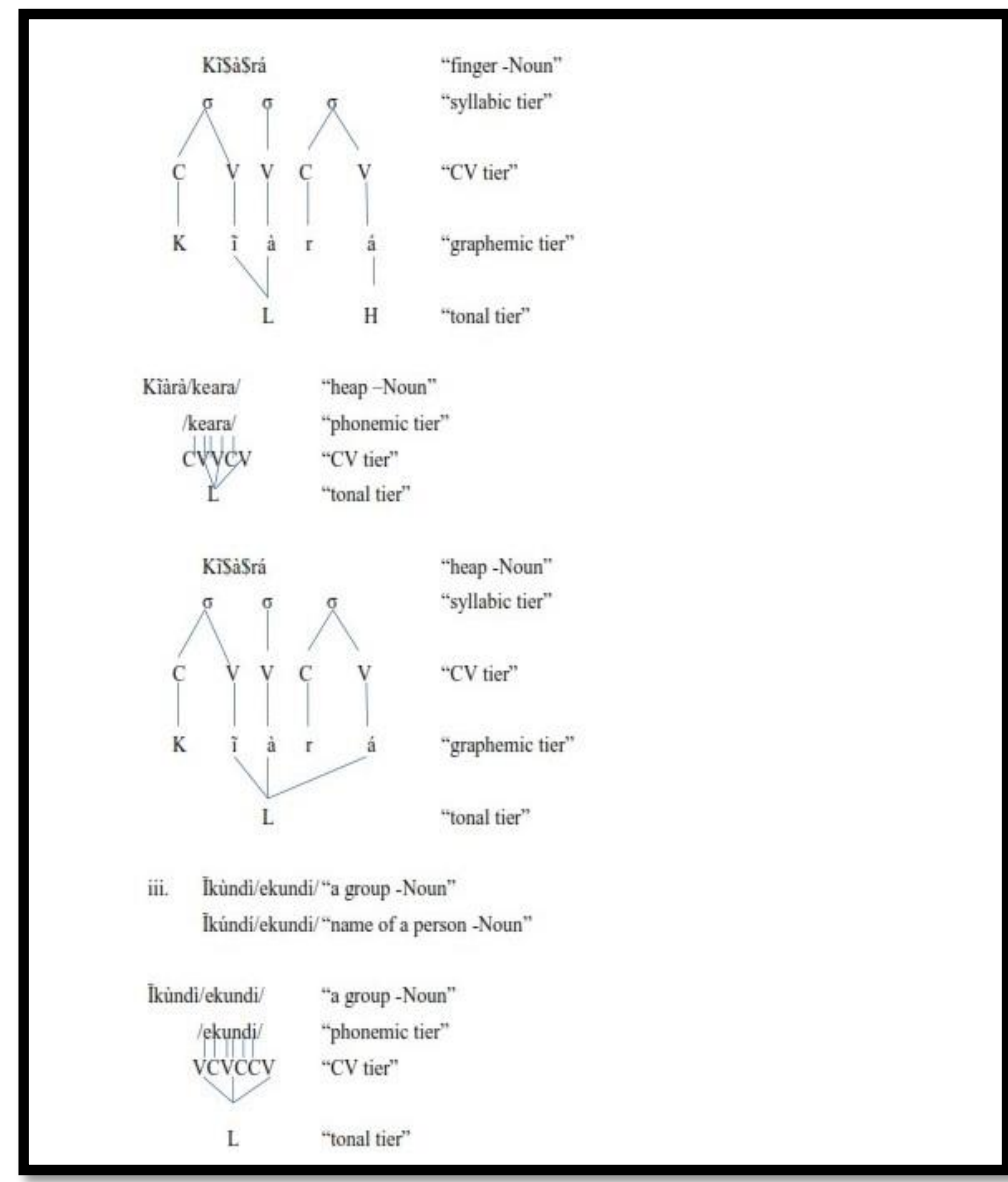

Figure 12

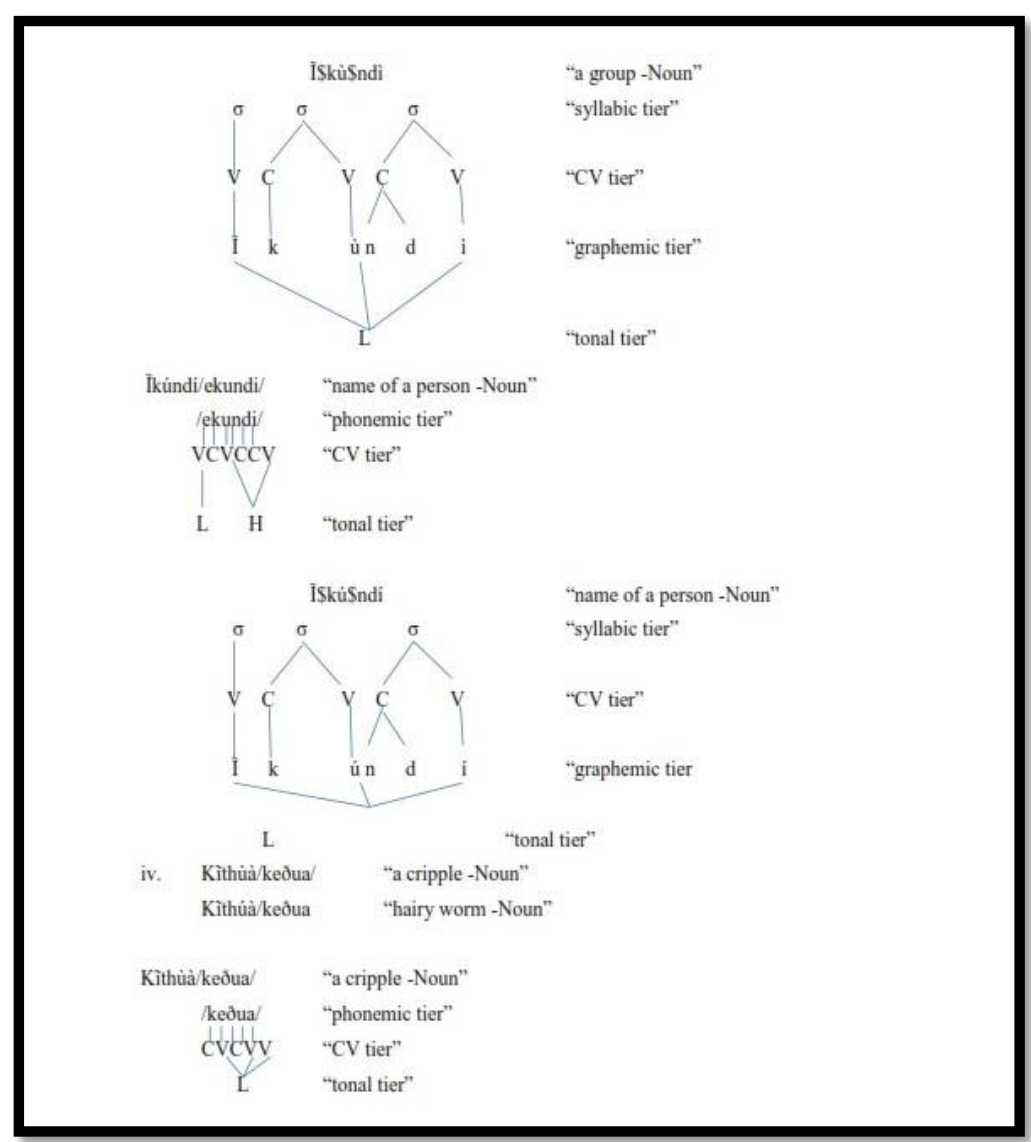

Figure 13 


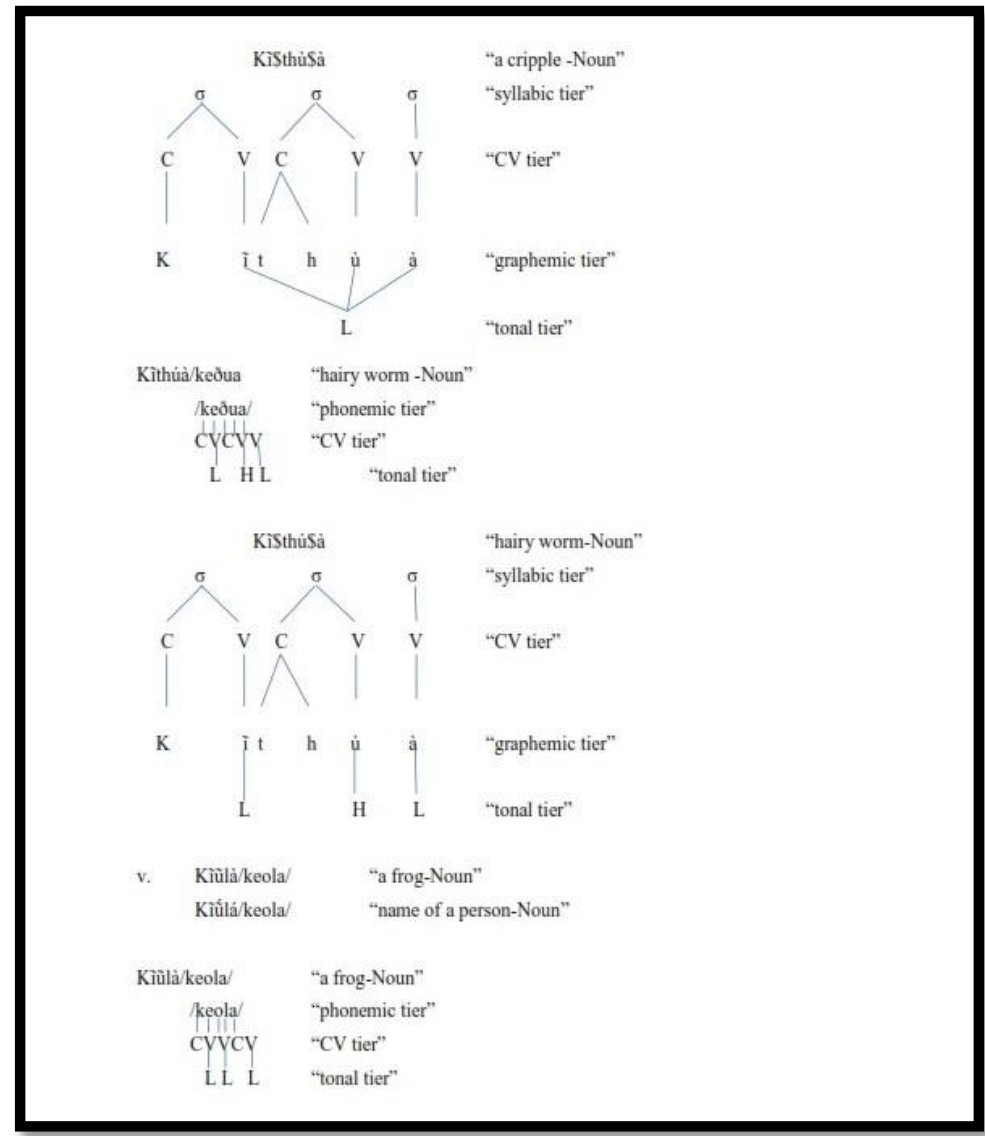

Figure 14

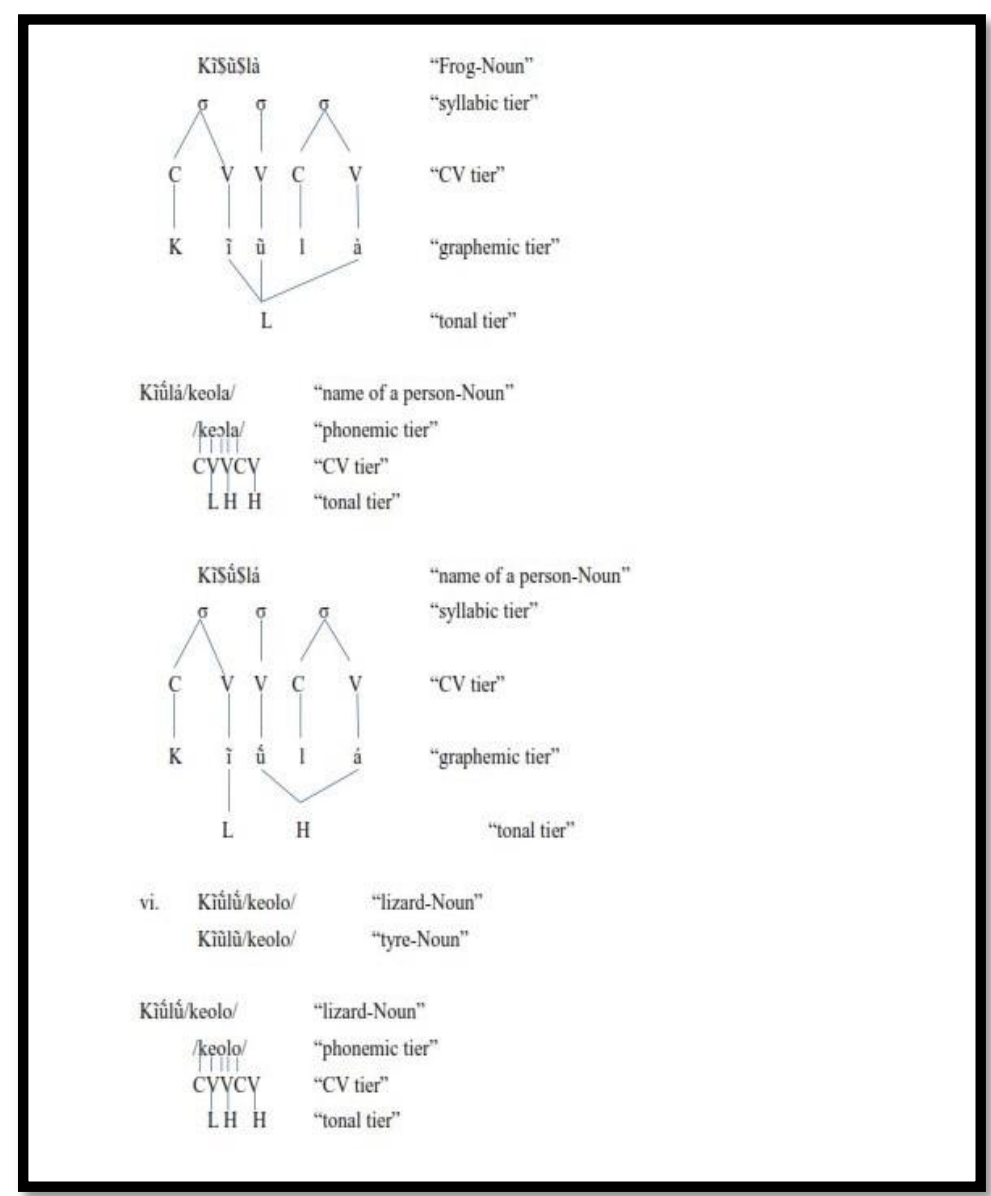

Figure 15 


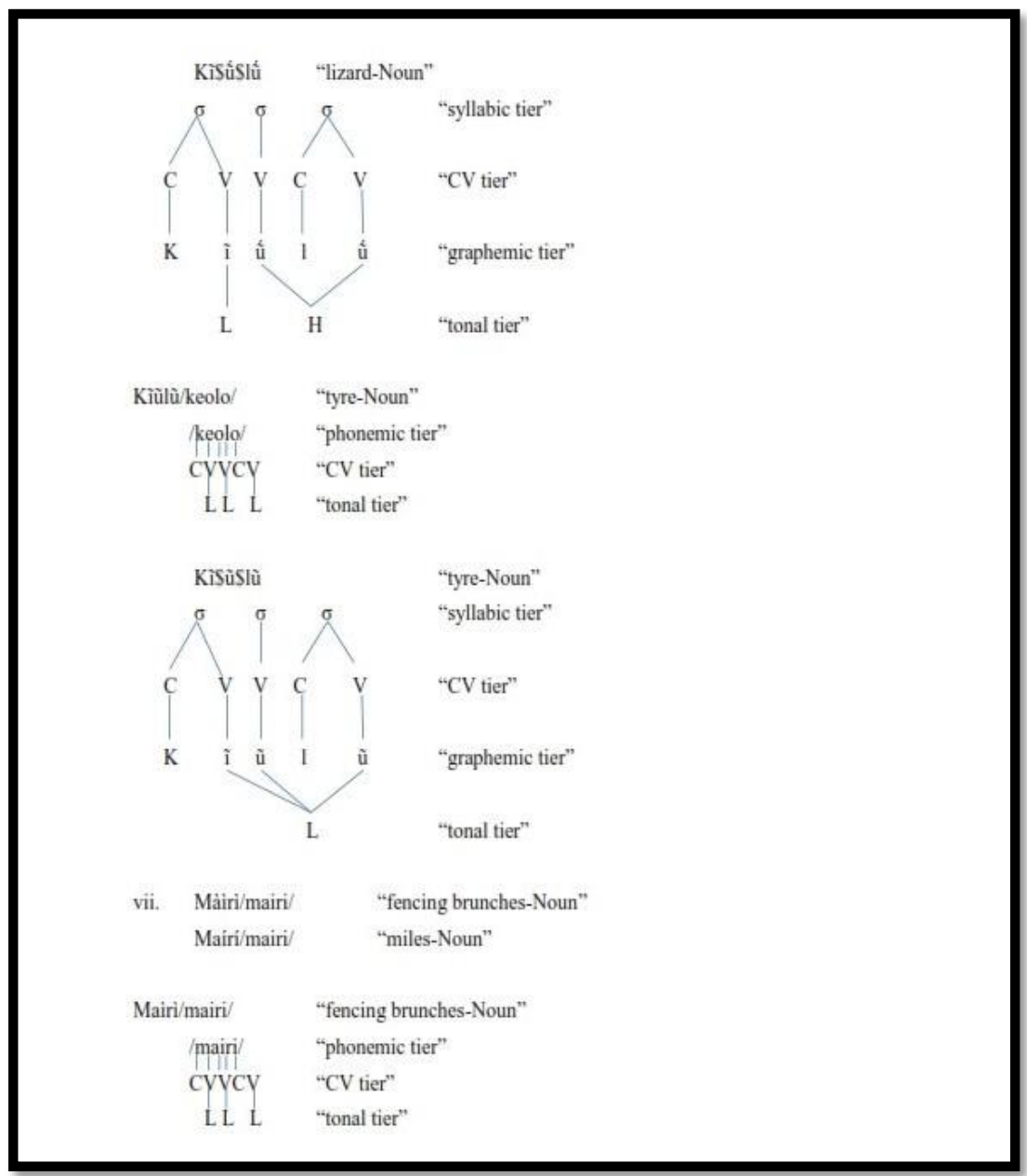

Figure 16

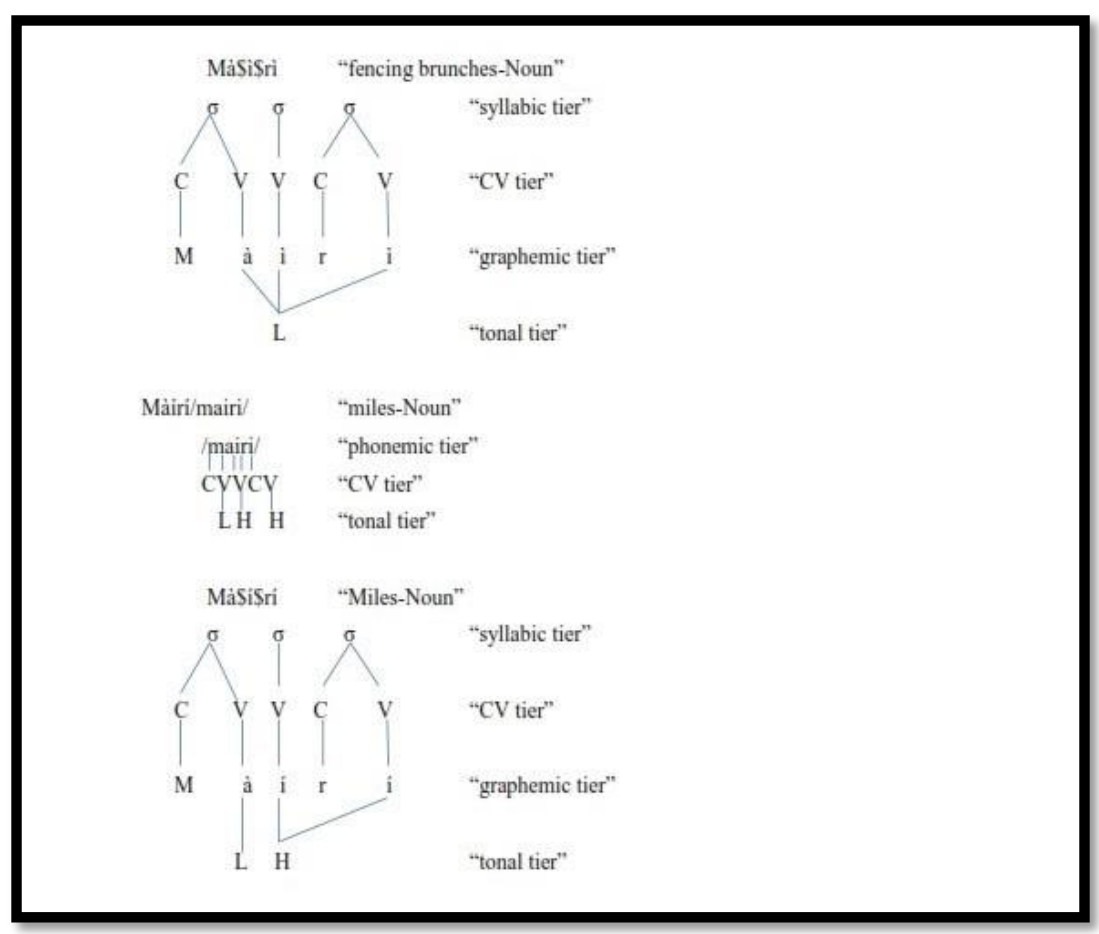

Figure 17

From the above illustrations, the monosyllabic nouns whose difference in meaning is brought about by tone demonstrate both high and low tonal patterns while the bi-syllabic nouns that are tonally distinctive in Gĩtigania show the HH, LL, HL, and LH tonal alterations. On the other hand, the tri-syllabic demonstrates LHH, LLL, and HHH tone patterns, where similar tones can be collapsed in line with the Obligatory Contour Principle. It is further clear from the illustrations thatGĩtigania lexical items with similar segmental composition can be differentiated on basis of tone an indication that tone is minimally contrasting. 


\subsubsection{Lexical Function of Tone: Word Classes}

Other than differentiating word meaning in a grammatical category, tone also distinguishes the grammatical categories of words sharing identical segmental composition. Distinctive tones and tone patterns in Gĩtigania nouns and verbs are analysed and given an APT representation to foreground the distinctive role of tone as shown below:

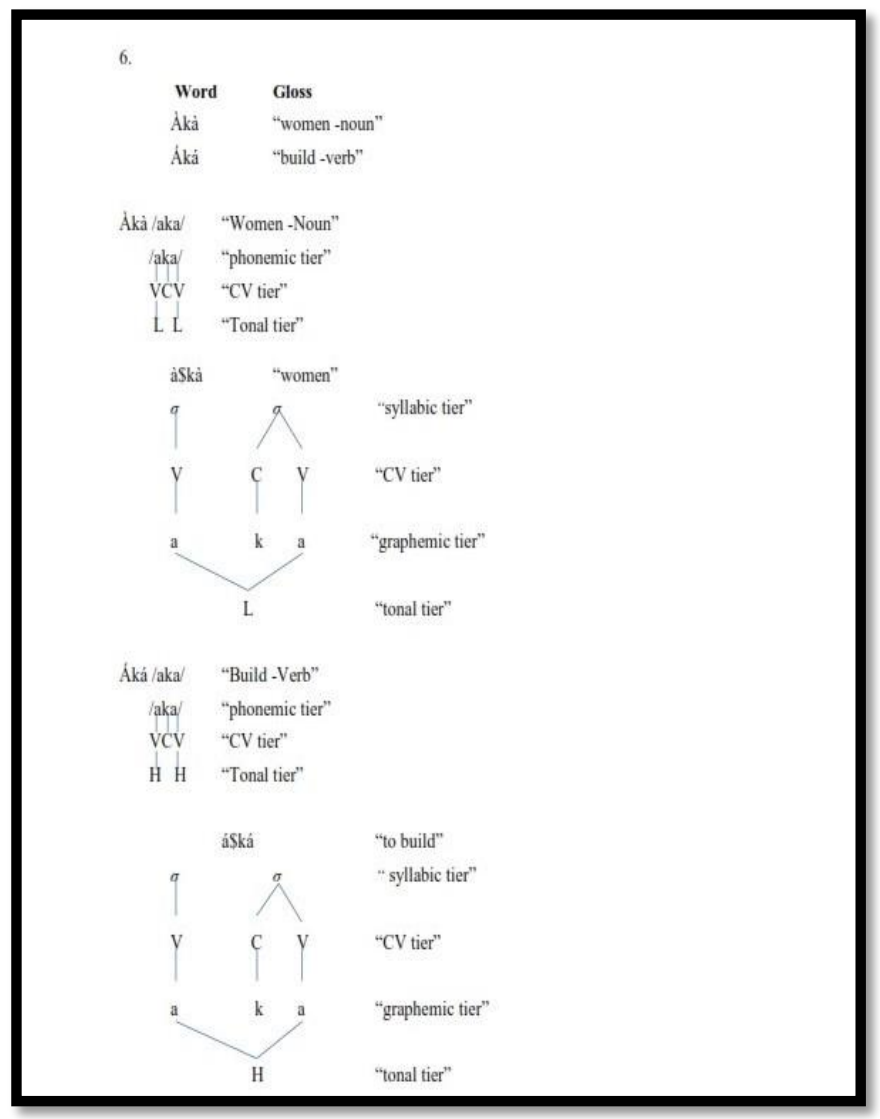

Figure 18

Similarly, all the other examples can be illustrated using tone labels and APT structural diagrams as shown above.

Ànà

'children-noun'

Áná

'go home -verb'

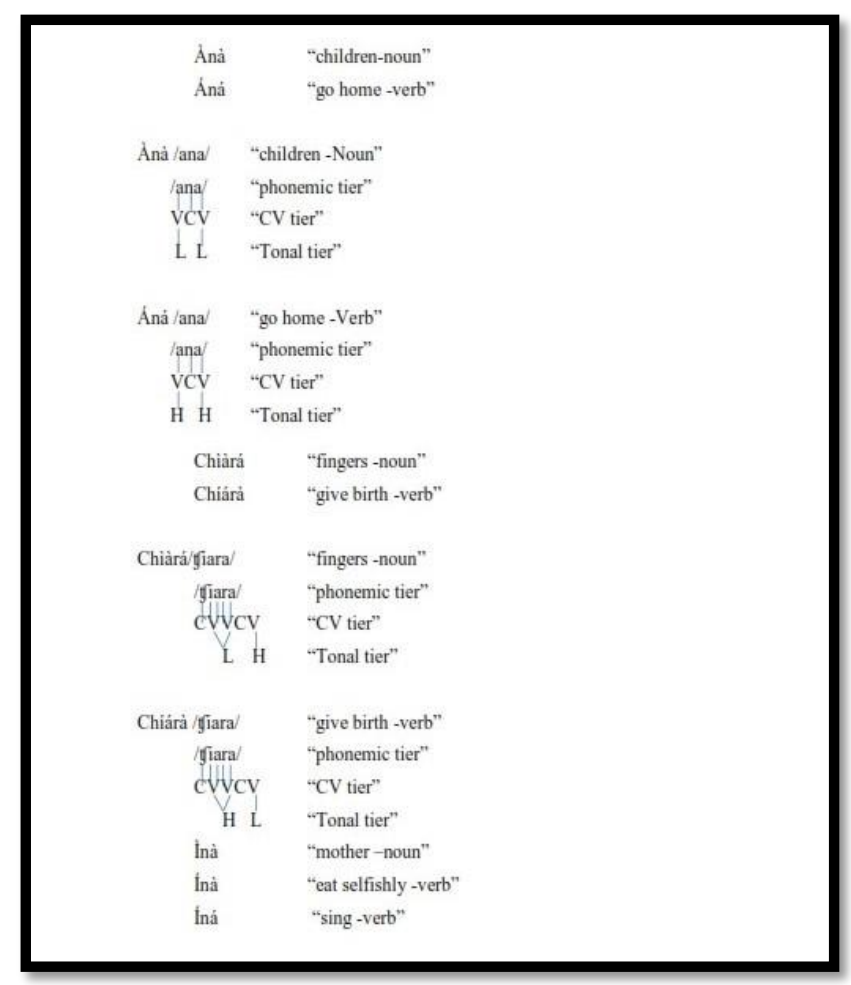

Figure 19 


$$
\begin{aligned}
& \text { Inà /ina/ "mother -Noun" } \\
& \text { /ina/ "phonemic tier" } \\
& \text { VCV "CV tier" } \\
& \text { L L "Tonal tier" }
\end{aligned}
$$

Figure 20

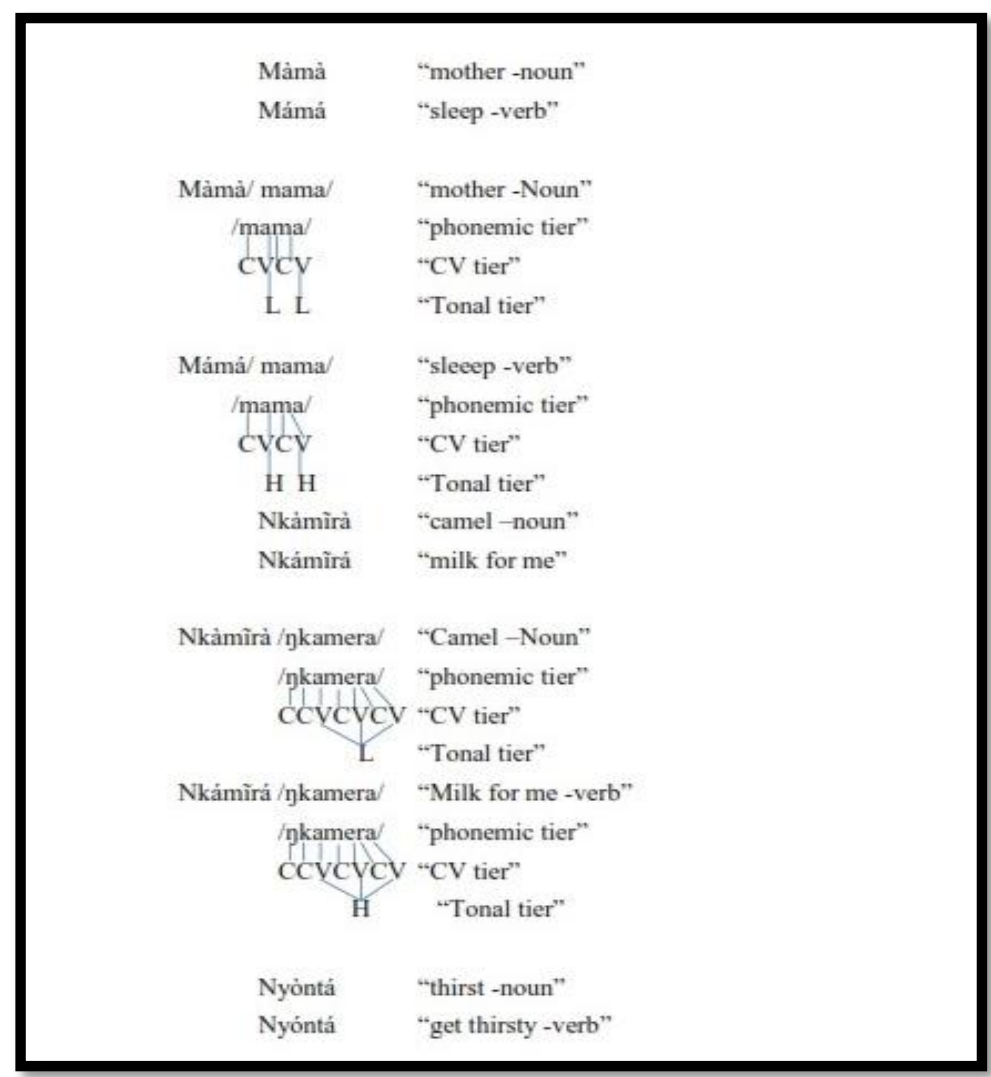

Figure 21 


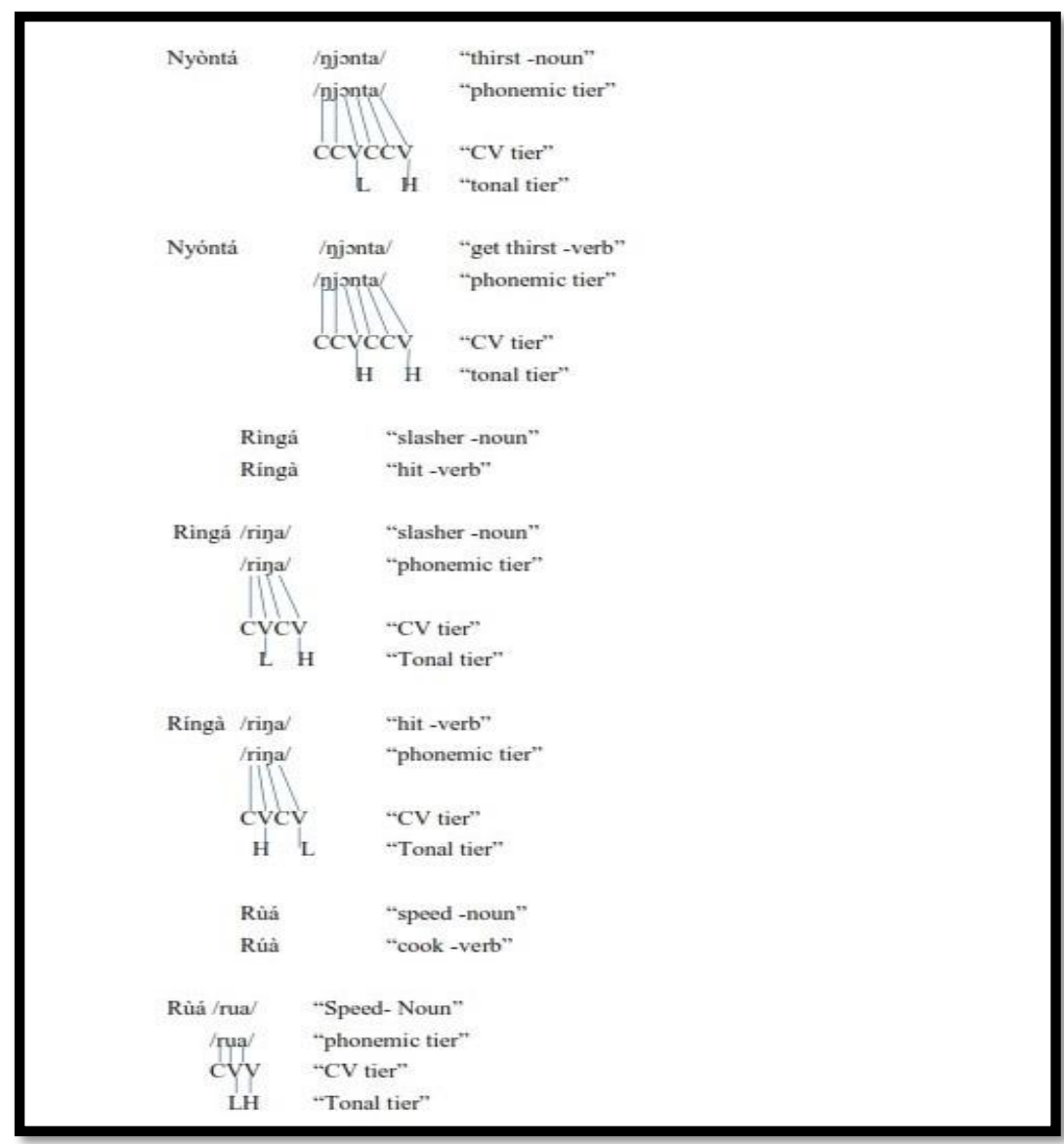

Figure 22

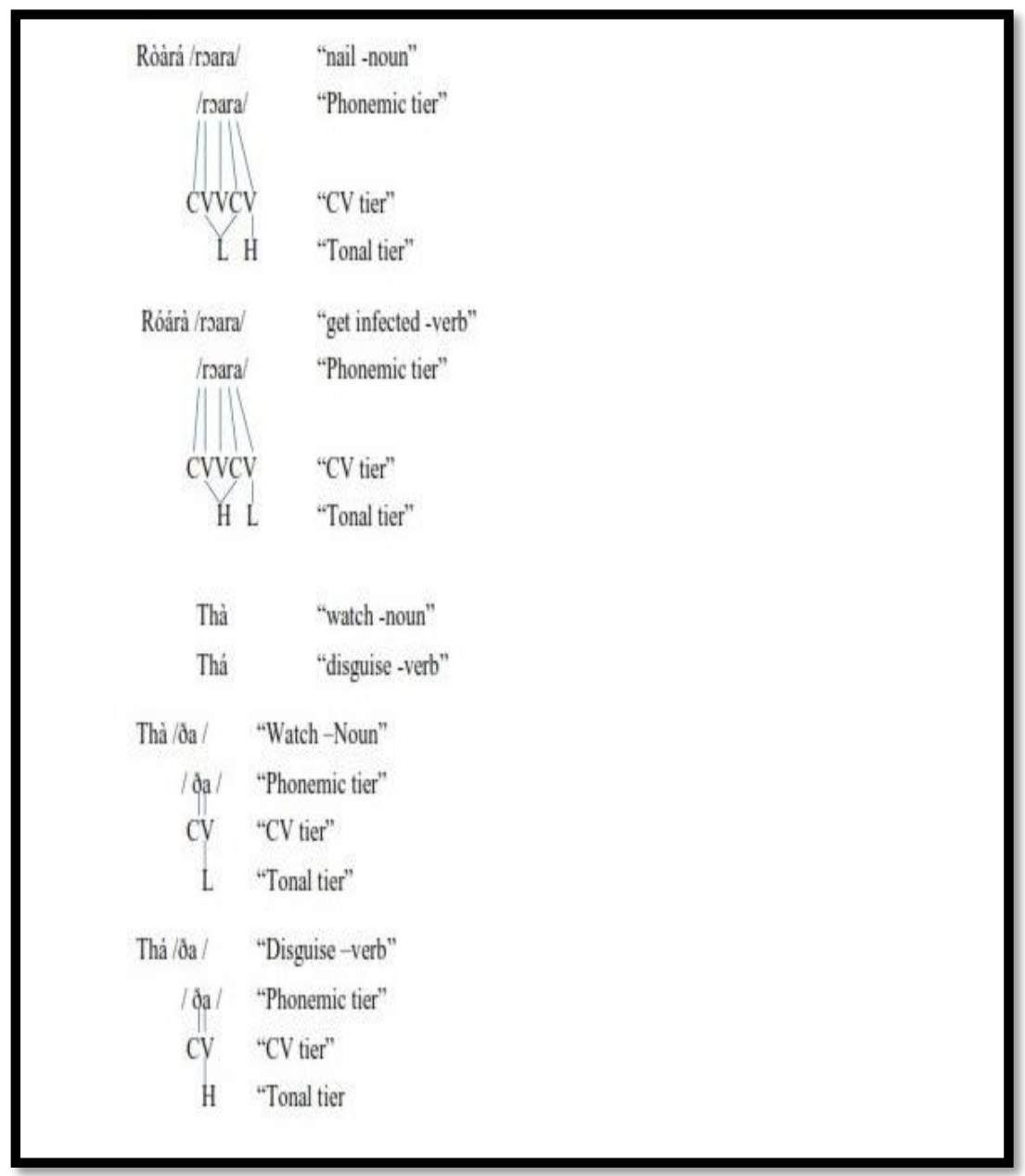

Figure 23 


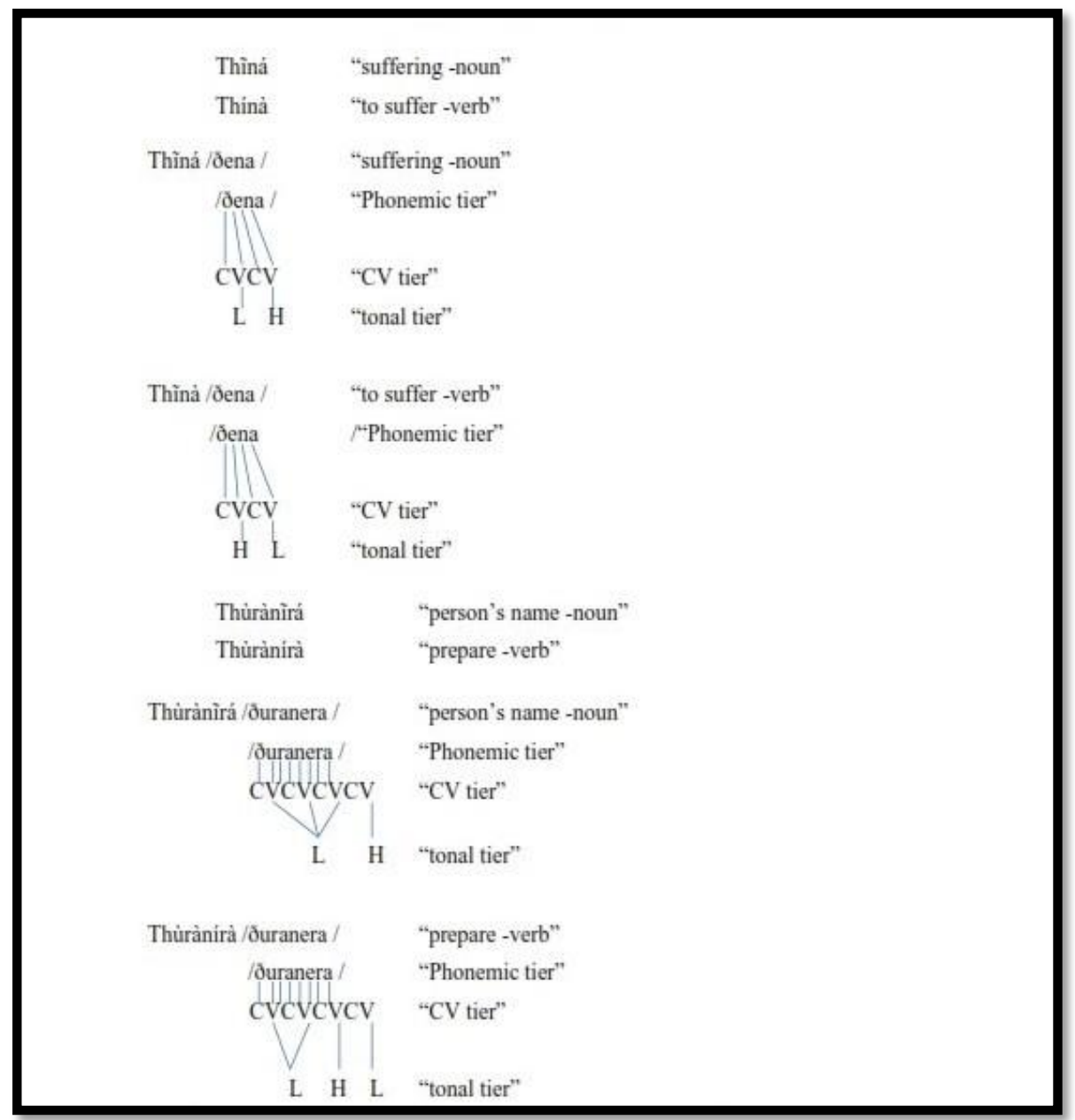

Figure 24

From the above data, tone distinguishes word classes in similar segments. Monosyllabic nouns and verbs manifest $\mathrm{L}$ and $\mathrm{H}$ tonal patterns respectively. While bi-syllabic nouns demonstrate LL and LH tonal patterns, the verbs adopt $\mathrm{HH}$ or HL tones.

\section{Conclusion}

This paper described the various levels of tone in Gĩtigania. Though Gĩtigania demonstrates two level tones; Low (L) and High $(\mathrm{H})$, there are few incidences of contour tones which are either rising or falling. Gĩtigania tone serves a distinctive function where it not only distinguishes meaning in similar segments but also word classes. This paper also emphasises on the importance of tone marking in Gĩtigania as there seems to be a wide range of minimal pairs whose difference is brought about by tone marking thus failure to mark tone may bring about communication breakdown.

\section{References}

i. Aderibigbe, A. (2012). Verbal Afkes in Afro Language. An unpublished paper presentation submitted to department of Languge and Linguistics, Nasarawa state University, Keffi.

ii. Chomsky, N. and Halle, M. (1968). The sound patterns of English. New York: Hamper and Row.

iii. Goldsmith, J. A. (1976). Autosegmental phonology. A Dissertation for the Degree of Doctor in Philosophy. Massachusetts Institute of Technology.

iv. Goldsmith, J. A. (1990). Autosegmental and metrical phonology. Oxford: Basil Blackwell Ltd.

v. Hyman, L. (1976). The Autosegmental distinction of tonal language types.

vi. Marete, G. (1981). A study of Grammatical agreement in Kimeru syntax: A Transformational Approach, MA thesis: University of Nairobi.

vii. Mutiga, J., M. (2002). The tone system of Kikamba: A case study of Mwingi dialect. Unpublished Doctoral Thesis, University of Nairobi.

viii. Nkamigbo, L.C (2010). Phonology in Teacher Education in Nigeria: The Igbo Language Example. African Journal of Teacher Education Vol. 1 No. 1

ix. Phillipson, G. (1998). Tone reduction vs. Metrical attraction in the evolution of Eastern Bantu Systems. Stanford: CSLI Publications

x. Pike, K. (1948). Tone languages. University of Michigan Publications in Linguistics. No. 4. Ann Arbor: University of Michigan Press.

xi. Welmers, (1973). African language structures. London: University of California Press. 